\title{
Curative and Prophylactic Surgery of Young-onset Colorectal Cancer in Inherited Syndromes: A 15-Year Monocentric Retrospective Experience
}

\author{
EDOARDO VIRGILIO ${ }^{1}$, GENOVEFFA BALDUCCI $^{1}$, PAOLO MERCANTINI $^{1}$, MARIO FERRI $^{1}$, \\ ANTONIO PALUMBO ${ }^{2}$, EMANUELA PILOZZI ${ }^{2}$ and MARCO CAVALLINI ${ }^{1}$ \\ ${ }^{1}$ Department of Medical and Surgical Sciences and Translational Medicine, \\ Faculty of Medicine and Psychology, Sapienza University, St. Andrea Hospital, Rome, Italy; \\ ${ }^{2}$ Department of Clinical and Molecular Medicine, Faculty of Medicine and Psychology, \\ Sapienza University, St. Andrea Hospital, Rome, Italy
}

\begin{abstract}
Background/Aim: Although genoproteomic and clinicopathological knowledge on Lynch syndrome $(L S)$ and familial adenomatous polyposis (FAP) has notably increased during the past two decades and even though surgery represents the mainstay of treatment for both conditions, as of 2019, the surgical choice in terms of timing and procedure still appears controversial in the absence of definitive guidelines. Materials and Methods: Data were retrospectively analyzed of patients with colorectal cancer (CRC) surgically treated at our Institution between 1st January 2003 and 31st December 2018. Particular attention was given to patients with $L S$ and FAP $\leq 45$ years of age (young-onset CRC); for this category of patients, the surgical procedures performed were compared in terms of benefits and disadvantages. Results: A total of 1,878 primary CRCs were submitted to major surgery; young-onset malignancies accounted for $3.8 \%$ of all CRCs. Thirteen youngonset inherited CRCs were surgically removed from 11 patients with LS and two with FAP. Segmental colectomy and restorative proctocolectomy were the procedures most frequently performed in young patients with LS and FAP, respectively. Conclusion: In the light of our retrospective results, we highlight the need for randomized controlled trials comparing the surgical options for LS- and FAP-related CRC developing in young patients. Defining the advantages and risks of each surgical option is of the utmost importance in
\end{abstract}

Correspondence to: Professor Edoardo Virgilio, Medical and Surgical Sciences and Translational Medicine, Faculty of Medicine and Psychology, Sapienza University, St. Andrea Hospital, via di Grottarossa 1035-39, 00189, Rome, Italy. Tel: +39 0633775693, Fax: +390633775322, e-mail: aresedo1992@yahoo.it, edoardo.virgilio@uniroma1.it

Key Words: Colorectal cancer, Lynch, HNPCC, FAP, colectomy, proctocolectomy, IRA, IPAA. order to improve prognosis of such patients and establish unanimous recommendations.

With over 1.8 million new cases and 881,000 deaths, in 2018 colorectal cancer (CRC) ranked third in terms of worldwide incidence and second in terms of cancer-related mortality (1). Young-onset CRC, between the ages of 20 and 49 years, accounts for $2-8 \%$ of all CRC (2). Compared to late-onset $\mathrm{CRC}$, young-onset $\mathrm{CRC}$ shows an increasing incidence and a more aggressive behavior (2). This is probably due to a different molecular profile: $15-20 \%$ of cases, in fact, have a strong hereditary component with well-recognized molecular alterations (3). Nevertheless, just like late-onset CRC, most cases are sporadic and the pathogenic mechanisms remain to be elucidated (2-5). The two most frequent and best-known syndromes of dominantly inherited CRC are Lynch syndrome (LS) and familial adenomatous polyposis (FAP) (6). LS (previously known as hereditary non-polyposis CRC syndrome, HNPCC) is the more common condition, accounting for approximately $2-4 \%$ of all CRC cases (6). In approximately $60 \%$ of families that meet the Amsterdam-I criteria, LS is associated with an identified germline defect (classical LS, $30 \%$ ) or deficient expression (Lynch-like tumors, Lynch tumor or suspected LS, 70\%) in at least one of the DNA mismatch repair (MMR) anti-oncogenes such as mutL homolog 1 (MLH1) and mutS homolog 2 (MSH2) (80-90\% of cases), MSH6 and postmeiotic segregation increased 2 (PMS2) (10$20 \%)$, and epithelial cell adhesion molecule (EPCAM) (3\%) (710). The remaining $40 \%$ of families, however, do not carry any altered profile in genes, proteins or microsatellite instability and genetic causes are still unknown; such members are diagnosed as having familial CRC type $\mathrm{X}$ (11). FAP is responsible for $\leq 1 \%$ of all CRC cases, entails a $100 \%$ risk of developing CRC, and exhibits more than 100 colorectal adenomatous polyps and no familial history (de novo FAP) in almost $30 \%$ of cases (12). There are two further inherited 
syndromes similar to classical FAP: attenuated FAP (AFAP) and homo sapiens mutY DNA glycosylase (MUTYH)associated polyposis (MAP). Like FAP, AFAP also results from autosomal dominant mutations of adenomatous polyposis coli $(A P C)$ gene but shows fewer colorectal polyps (10-100) and less aggressive nature; the clinical phenotype of MAP mimics that of AFAP, but is due to a biallelic recessive mutations of MUTYH gene (12). Although genoproteomic and clinicopathological knowledge on the descriptive hereditary syndromes has improved and even though surgery is universally acclaimed as the only curative method in most circumstances, as of 2019, no standardized guideline exists on the choice of the best curative technique or the most appropriate time to perform prophylactic treatment $(6,12)$. We report our 15-year surgical experience with young-onset CRC associated with these hereditary disorders.

\section{Materials and Methods}

We retrospectively analyzed data from patients with CRC surgically treated at our hospital (St. Andrea Hospital, Faculty of Medicine and Psychology, Sapienza University, Rome, Italy) in the time elapsed since its establishment (1st January 2003) to 31st December 2018. Those with FAP without CRC but submitted to prophylactic surgery were also included. Clinicopathologic, surgical, histopathological and molecular features of in-patients with CRC were obtained consulting paper records (2003-2007) and, more recently, electronic registry system (2008-2018). Protection of anonymity was assured following the ethical standards of 1964 Declaration of Helsinki and its later amendments. Follow-up of patients with young-onset CRC was conducted by telephone or email interviews. Although there is no unanimous consensus for delineating the exact age range for youngonset CRC, the age threshold being somewhat variable through the literature (ranging from 39 to 50 years), for our study we elected patients aged 45 years and younger following the original Bethesda guidelines (2). For such patients, diagnosis of LS, Lynch-like or sporadic tumor was confirmed with microsatellite instability analysis through determination of BAT 25, BAT 26, D2S123, D5S346, D18S69 or D17S250 (ABI PRISM ${ }^{\circledR} 3100$ Genetic Analyzer, GeneScan ${ }^{\mathrm{TM}}$; Applied Biosystems and Hitachi, Ltd., Foster City, CA, USA) and immunohistochemical assessment of MMR proteins. More precisely, as mentioned before, CRC was classified as being associated with LS in the presence of genomic instability using a reference panel of five microsatellite markers (BAT 25, BAT 26, D2S123, D5S346, D18S69 or D17S250) whereas Lynch-like tumor was diagnosed in cases of genomic stability (MSS) accompanied by loss of nuclear expression of MMR proteins in cancer tissue. Finally, CRCs were assessed as sporadic when MSS was associated with maintained nuclear expression at immunohistochemistry and lack of a family history of malignancy (6-11).

\section{Results}

Our 15-year retrospective analysis demonstrated that 1,878 primary CRCs (1124 colonic, and 754 rectal/anal) were submitted to major surgery (hemicolectomy, sub/total colectomy, proctocolectomy, low anterior resection, abdomi-noperineal resection) at our Institution. Youngonset malignancies accounted for $3.8 \%$ of all CRCs (73 cases: 48 colonic and 25 rectal).

Table I shows the main features of patients with CRC affected by LS and Lynch-like disease (eight and three individuals, respectively) treated with resective surgery. Another LS case was detected in a 41-year-old woman with rectal cancer who died of widespread disease during exclusive chemotherapy (Table I). Segmental colectomy was the most common operation (six right colectomies, two left colectomies, three low rectal resections).

Table II presents the main characteristics of patients with FAP treated with curative or prophylactic surgery (two and six patients, respectively). Five individuals were first-degree relatives; we labeled their bloodline as Family $\mathrm{F}$ from Frosinone, their native town in Italy. Data from one female member have been already been published (13). Another two patients were siblings (Family A from Acerra, another small Italian town). Restorative proctocolectomy with protective ileostomy was the most frequent procedure (open and laparoscopic approach in six and two cases, respectively).

\section{Discussion}

Yielding a positive impact on their life expectancy, surgery represents the mainstay of treatment for patients with LS and FAP young-onset CRC $(6,12)$. Nevertheless, concerning surgical decision-making, as of 2019, there are no standardized definitive recommendations or unanimous consensus regarding the timing and selection of the best surgical procedure $(6,12)$. This is mainly due to the fact that, with the exception of some randomized controlled trials on chemoprevention, current guidelines (four for LS-related CRC and eight for FAP) are supported by level III evidence and derived from retrospective case-control studies (14-16). In this way, each case should be individually considered and carefully decided by a working team comprising surgeons, oncologists, gastroenterologists and genetic counselors (12). A surgical act in these patients must prevent death from cancer (with a curative and prophylactic intent) as well as preserve quality of life (6). Given the complexity and controversies of this argument, some authors have proposed performing surgery for inherited CRC only at specialized centers for hereditary malignancies (18).

Prophylactic surgery in young patients with LS. Presently, in LS patients without CRC, primary prophylactic surgery is not generally recommended except for selected cases with carcinophobia (individuals suffering from this anxiety disorder are overwhelmed by the chronic fear of developing cancer and prefer immediate surgery to lifelong endoscopic surveillance), aggressive familial phenotype and high penetrance $(6,17)$. There are several reasons discouraging 
Table I. Main clinicopathological, genoproteomic, surgical and oncological features of patients with young-onset colorectal affected by inherited syndromes.

\begin{tabular}{|c|c|c|c|c|c|c|c|c|c|}
\hline \multirow[b]{2}{*}{ Diagnosis } & \multirow[b]{2}{*}{ Gender } & \multirow[b]{2}{*}{$\begin{array}{l}\text { Age, } \\
\text { years }\end{array}$} & \multirow[b]{2}{*}{ Site } & \multirow[b]{2}{*}{$\begin{array}{l}\text { Genomic } \\
\text { instability }\end{array}$} & \multirow[b]{2}{*}{ IHC } & \multicolumn{3}{|c|}{ Surgery } & \multirow[b]{2}{*}{ Follow-up } \\
\hline & & & & & & Aim & Procedure & Complications & \\
\hline LS & M & 34 & $\mathrm{AC}$ & MSI & n.a. & Curative & RH & None & Healthy at 15 years \\
\hline LS & $\mathrm{F}$ & 36 & DC & MSI & n.a. & Curative & LH & None & Death from WMD \\
\hline LS & M & 28 & $\mathrm{AC}$ & MSI & n.a. & Curative & RH & None & Death from WMD \\
\hline LS & $\mathrm{F}$ & 45 & $\mathrm{AC}$ & MSI & n.a. & Curative & RH & None & Death from WMD \\
\hline LS & M & 45 & $\mathrm{AC}$ & MSI & hMLH1 & Curative & RH & None & Bladder cancer at 11 years (removed) \\
\hline LS & $\mathrm{F}$ & 43 & $\mathrm{AC}$ & MSI & hMSH2, hMSH6 & Curative & RH & None & Healthy at 4 years \\
\hline LS & M & 41 & TC & MSI & PMS2 & Curative & LH & $\begin{array}{l}\text { Repeat surgery } \\
\text { for PO AD }\end{array}$ & $\begin{array}{c}\text { Suspicion of PC } \\
\text { (PET-positive nodules) at } 2 \text { years }\end{array}$ \\
\hline LS & M & 31 & $\mathrm{AC}$ & MSI & hMLH1, PMS2 & Curative & RH & None & $\begin{array}{c}1 \text { AR at } 8 \text { years }(\mathrm{SC}) \\
1 \mathrm{AR} \text { at } 10 \text { years }(\text { IRA }+\mathrm{TI})\end{array}$ \\
\hline LL & M & 27 & $\mathrm{R}$ & MSS & hMLH1, PMS2 & Curative & $\mathrm{LAR}+\mathrm{TI}$ & None & $1 \mathrm{AR}$ at 8 years $(\mathrm{SC})$ \\
\hline LL & $\mathrm{F}$ & 42 & $\mathrm{R}$ & MSS & hMSH6 & Curative & $\mathrm{LAR}+\mathrm{TI}$ & None & Death from WMD \\
\hline LL & $\mathrm{F}$ & 33 & $\mathrm{R}$ & MSS & hMLH1, hMSH2 & Curative & $\mathrm{LAR}+\mathrm{TI}$ & None & Death from WMD \\
\hline LS & $\mathrm{F}$ & 41 & $\mathrm{R}$ & MSI & n.a. & Palliative & PAC & None & Death from WMD \\
\hline
\end{tabular}

AC: Ascending colon; DC: descending colon; F: female; IHC: Immunohistochemistry (loss of specific protein is indicated when available); LAR: low anterior resection; LH: left hemicolectomy; LL: Lynch-like syndrome.; M: male; MSI: microsatellite instability; MSS: microsatellite stability; n.a.: not assessed; PAC: port-a-cath insertion; PC: peritoneal carcinomatosis; PET: positron-emission tomography; PO AD: postoperative anastomotic dehiscence; R: rectum; RH: right hemicolectomy; SC: segmental colectomy: IRA: total colectomy with ileorectal anastomosis; TC: transverse colon; TI: temporary ileostomy; WMD: widespread metastatic disease.

Table II. Main clinicopathological, genoproteomic, surgical and oncological features of patients with young-onset familial adenomatous polyposis (FAP) suffering from colorectal cancer or large-bowel adenomas.

\begin{tabular}{|c|c|c|c|c|c|c|c|c|c|}
\hline \multirow[b]{2}{*}{ Gender } & \multirow[b]{2}{*}{$\begin{array}{l}\text { Age, } \\
\text { years }\end{array}$} & \multirow[b]{2}{*}{$\begin{array}{l}\text { Gravidity/ } \\
\text { parity }\end{array}$} & \multirow[b]{2}{*}{ Family } & \multirow[b]{2}{*}{$\begin{array}{l}\text { CRC } \\
\text { site }\end{array}$} & \multirow[b]{2}{*}{$\begin{array}{l}\text { Polyps, } \\
\text { n }\end{array}$} & \multirow[b]{2}{*}{$\begin{array}{c}A P C \\
\text { mutation }\end{array}$} & \multicolumn{2}{|c|}{ Surgery } & \multirow[b]{2}{*}{ Follow-up } \\
\hline & & & & & & & Aim & Procedure & \\
\hline $\mathrm{F}$ & 37 & NP & None & $\mathrm{AC}, \mathrm{DC}$ & $>100$ & n.a. & Curative & $\mathrm{RPC}+\mathrm{TI}$ & Pouchitis at 1 year; RU at 7 years \\
\hline M & 36 & - & $\mathrm{F}$ & None & n.f. & Codon 3238 del & Prophylactic & $\mathrm{RPC}+\mathrm{TI}$ & MDT at 1 year (removal and IT) \\
\hline $\mathrm{F}$ & 42 & MP & $\mathrm{F}$ & None & n.f. & Codon 3238 del & Prophylactic & $\mathrm{RPC}+\mathrm{TI}$ & Healthy at 15 years \\
\hline $\mathrm{F}$ & 26 & NP & $\mathrm{F}$ & Rectum & $>100$ & Codon 3238 del & Curative & $\mathrm{RPC}+\mathrm{TI}$ & Death for MDT at 1 year \\
\hline M & 26 & - & $\mathrm{F}$ & None & n.f. & Codon 3238 del & Prophylactic & $\mathrm{RPC}+\mathrm{TI}$ & Healthy at 6 months \\
\hline M & 16 & - & None & None & n.f. & n.a. & Prophylactic & $\mathrm{RPC}+\mathrm{TI}$ & $\begin{array}{c}\text { DCA at } 12 \text { years treated with PD; } \\
\text { PP and RP at } 15 \text { years }\end{array}$ \\
\hline $\mathrm{F}$ & 44 & MP & A & None & $>100$ & n.f. & Prophylactic & $\mathrm{L} \mathrm{RPC}+\mathrm{TI}$ & Healthy at 8 years \\
\hline M & 43 & - & $\mathrm{A}$ & None & $>100$ & n.f. & Prophylactic & $\mathrm{L}$ RPC+TI & Healthy at 8 years \\
\hline
\end{tabular}

AC: Ascending colon; APC: adenomatous polyposis coli; DC: descending colon; DCA: duodenal cancerized adenoma; del: deletion; Family A: same family from the town of Acerra (Italy); Family F: same family from the town of Frosinone (Italy); IT: intestinal transplant; L: laparoscopy; MDT: mesenteric desmoidal tumor; MP: pluriparous; n.a.: not assessed; n.f.: none found; NP: nulliparous; PD: pancreatoduodenectomy; PP: pouch polyps; RP: rectal polyps; RPC: restorative proctocolectomy; RU: rectal ulcer; TI: temporary ileostomy.

prophylactic sub-total colectomy in these patients: $20-40 \%$ of mutation carriers will never develop CRC due to incomplete penetrance and, therefore, would be operated on in vain and exposed to a worse quality of life with diarrhea or incontinence; lifelong surveillance of the rectal remnant would remain necessary; the high risk of extracolonic cancer would not be reduced, especially in LS type II, Turcot and Muir-Torre syndrome; the risk of developing CRC decreases in older patients; theoretically, since the organ in which the index cancer will arise is not predictable, there is no end of 
prophylactic surgery in patients with LS $(18,19)$. Secondary prophylactic surgery implies extended to total resection of the large bowel in patients with LS with CRC, whereas tertiary colorectal prophylaxis is performed for patients with CRC when LS diagnosis is achieved postoperatively; in both cases, the purpose of surgery is to reduce the incidence of metachronous CRC since, as reported by the retrospective literature, the risk of such an event after segmental colectomy of LS CRC can be as high as $50 \%$ after 10 years $(6,19)$. For postmenopausal or multiparous women with LS undergoing colorectal surgery, prophylactic total abdominal hysterectomy with bilateral salpingo-oophorectomy is strongly advised considering that the lifetime risk of endometrial cancer in these patients is 27 to $71 \%(15,20)$.

Curative surgery of patients with $L S$ with young-onset CRC. As mentioned before, there are no randomized controlled trials comparing different surgical procedures for young patients with LS developing CRC (19). For colonic cancer, the surgical options include segmental resection (hemicolectomy) or total abdominal colectomy with ileorectal anastomosis (TAC-IRA) (21). Currently, although some authors support the former plus yearly colonoscopy, laparoscopic TAC-IRA is the recommended procedure, although causing significantly more frequent defecation, and the risk of metachronous cancer in the rectal remnant is still high (3-12\% at $10-12$ years); in both cases lifelong proctoscopy is strongly advised (21). When performing an IRA, there is no recommendation favoring one anastomotic method over another (stapled vs. handsewn, end-to-end $v s$. end-to-side) (21). Rectal cancer in LS is common (20-30\% of patients) and represents the index cancer in 15 to $24 \%$ of cases (21). The optimal surgical treatment for rectal cancer is controversial including segmental (proctectomy alone with colorectal anastomosis, low anterior resection with colorectal or coloanal anastomosis or abdominoperineal resection) or extended resection [total proctocolectomy with end ileostomy (TPC) or restorative proctocolectomy with ileal pouch-anal anastomosis (RPC-IPAA) with or without temporary ileostomy (TI)] $(6,21)$. Proctectomy alone should always be avoided as retrospective studies have demonstrated colonic cancer occurrence in 15 to $54 \%$ of patients with LS after this kind of surgery (21). In locally advanced cancer, if a J pouch has been scheduled, chemoradiation should be performed before intervention to minimize the risk of pouchitis (as occurred in one of our patients) (19).

Prophylactic and curative surgery of young patients with FAP. As of 2019, there are no definitive guidelines regarding the choice and timing of surgery and most patients undergo surgery between 15 and 25 years of age (12). Exceptions to this general rule deferring surgery on a year-to-year basis are represented by some classes of FAP (patients asymptomatic without adenomas $>9 \mathrm{~mm}$ and high-grade dysplasia or at high risk of desmoid disease), AFAP or MAP $(6,12)$. Three surgical options are available: TPC, TAC-IRA and RPC-IPAA (12). TPC is the operation less commonly performed due to its extremely destructive nature; nevertheless, it is still taken into account for patients with very low rectal cancer with sphincter dysfunction and when a mesenteric desmoid tumor (MDT) prevents pulling the small bowel down to the pelvis and pouch construction (12). As a consequence, most choices are between IRA and IPAA $(6,12)$. Being a form of rectal-sparing prophylactic colectomy, IRA is not recommended when dealing with a diseased rectum (or colon) and should be reserved for patients with mild FAP, AFAP and MAP that agree to undergo yearly follow-up (12). Compared to IPAA, IRA has the least degree of desmoid risk and entails a more limited pelvic dissection, leading to a better quality of life with less frequent defecation and fewer urinary and sexual dysfunctions (male impotence and female infertility) $(6,12,20)$. IPAA was the most common procedure in patients with FAP in the past: it is indicated in the presence of profuse polyposis, colonic and rectal cancer, and, despite its complexity, has a very low rate of mortality $(0.5-1 \%)(12)$. Laparoscopy is the best approach for young women as it leads to fewer pelvic adhesions affecting the fallopian tubes and is therefore associated with a higher pregnancy rate $(6,12)$. Traditionally, TI has been performed during open IPAA to prevent anastomotic leakage, fistulation and pelvic sepsis; since such complications have been rarely described during laparoscopic IPAA, the selection criteria for omitting or accomplishing a protective TI in this laparoscopic procedure still need to be clarified (12). Differently from the past, when the oncological risk was considered abolished after surgical removal, we are now aware that adenomas and cancer may develop within the ileal pouch, the rectal remnant mucosa (often, in IPAA, a 1 to $2 \mathrm{~cm}$ cutoff of rectal mucosa is left above the anus) and TI even many years following IPAA $(6,12,14,22)$. Pouch polyposis seem more common after manual anastomosis, whereas polyps at the anal transition zone are more frequent after the use of stapling devices $(6,12)$; as a consequence, such sites (including TI mucosa) should be checked through annual endoscopy $(6,14)$. One of our patients developed a rectal ulcer 7 years after IPAA, whereas polyposis did not occur in any patient. Other surgical procedures in patients with FAP include duodenectomy, pancreatoduodenectomy removal of desmoid tumors and intestinal transplant $(15,16)$. Duodenectomy or pancreatoduodenectomy are performed in the presence of duodenal adenomas with high-grade dysplasia: in our series, we re-operated one young male patient developing a duodenal adenocarcinoma 12 years after IPAA. Some patients with FAP are also at higher risk of developing desmoid tumors in the abdominal wall and mesentery $(15,16)$. Removal of the former is not technically demanding and therefore should be always performed $(16,22)$. On the other hand, occurrence of MDT 
represents a complex topic in patients with FAP; in these cases, the role of surgery is in fact controversial, especially for aggressive forms $(15,16,20)$. In our series, two first-degree relatives developed MDTs after IPAA: in one case the tumor was easily excised and followed by a small bowel transplantation, whereas MDT was rapidly growing and fatal in the other patient (13).

\section{Conclusion}

Our retrospective study highlights the necessity for randomized controlled trials comparing the surgical options for LS- and FAP-related CRC developing in young patients. The absence of these kinds of studies precludes reliable assessment of the advantages and risks of each surgical option, and prevents establishing definitive guidelines and improving the prognosis of such patients.

\section{Conflicts of Interest}

The Authors declare no conflicts of interest.

\section{Authors' Contributions}

Dr. Virgilio conceived the presented research. Dr. Virgilio, Dr. Palumbo and Dr. Pilozzi performed the histopathological, immunohistochemical and genomic analysis. Dr. Virgilio, Dr. Mercantini and Dr. Ferri developed the clinicopathological and surgical analysis. Dr. Virgilio wrote the article. Dr. Balducci and Dr. Cavallini helped supervise the entire project. All the Authors agree with the content of the article.

\section{References}

1 Bray F, Ferlay J, Soerjomataram I, Siegel RL, Torre LA and Jemal A: Cancer Statistics 2018: GLOBOCAN estimates of incidence and mortality worldwide for 36 cancers in 185 countries. CA Cancer J Clin 68: 394-424, 2018. PMID: 30207593. DOI: $10.3322 /$ caac.21492

2 Ballester V, Rashtak S and Boardman L: Clinical and molecular features of young-onset colorectal cancer. World J Gastroenterol 22: 1736-1744, 2016. PMID: 26855533. DOI: 10.3748/ wjg.v22.i5.1736

3 Silla IO, Rueda D, Rodríguez Y, García JL, de la Cruz Vigo F and Perea J: Early-onset colorectal cancer: a separate subset of colorectal cancer. World J Gastroenterol 20: 17288-17296, 2014. PMID: 25516639. DOI: 10.3748/wjg.v20.i46.17288

4 Pilozzi E, Ferri M, Onelli MR, Mercantini P, Corigliano N, Duranti E, Dionisi L, Felicioni F, Virgilio E, Ziparo V and Ruco L: Prognostic significance of $18 \mathrm{q} \mathrm{LOH}$ in sporadic colorectal carcinoma. Am Surg 77: 38-43, 2011. PMID: 21396303.

5 Ferri M, Lorenzon L, Onelli MR, La Torre M, Mercantini P, Virgilio E, Balducci G, Ruco L, Ziparo V and Pilozzi E: Lymph node ratio is a strong prognostic factor than microsatellite instability in colorectal cancer patients: Results from a 7 years follow-up study. Int J Surg 11: 1016-1021, 2013. PMID: 23747976. DOI: 10.1016/j.ijsu.2013.05.031
6 Church JM: Controversies in the surgery of patients with familial adenomatous polyposis and Lynch syndrome. Familial Cancer 15: 447-451, 2016. PMID: 26869170. DOI: 10.1007/ s10689-016-9886-4

7 Da Silva FC, Wernhoff P, Dominguez-Barrera $\mathrm{C}$ and Dominguez-Valentin M: Update on hereditary colorectal cancer. Anticancer Res 36: 4399-4406, 2016. PMID: 27630275. DOI: 10.21873/anticanres.10983

8 Kamiza AB, Wang WC, You JF, Tang R, Wang YT, Chien HT, Lai CH, Chiu LL, Lo TP, Hung KY, Hsiung CA and Yeh CC: EGFR, SMAD7, and TGFBR2 polymorphisms are associated with colorectal cancer in patients with Lynch syndrome. Anticancer Res 38: 5983-5990, 2018. PMID: 30275229. DOI: 10.21873/anticanres.12946

9 Arakawa K, Hata K, Kawai K, Tanaka T, Nishikawa T, Sasaki K, Shuno Y, Kaneko M, Hiyoshi M, Emoto S, Murono K and Nozawa $\mathrm{H}$ : Predictors for high microsatellite instability in patients with colorectal cancer fulfilling the revised Bethesda guidelines. Anticancer Res 38: 4871-4876, 2018. PMID: 30061262. DOI: 10.21873 /anticanres. 12800

10 Tanakaya K, Yamaguchi T, Ishikawa H, Hinoi T, Furukawa Y, Hirata K, Saida Y, Shimokawa M, Arai M, Matsubara N, Tomita N, Tamura K, Sugano K, Ishioka C, Yoshida T, Ishida H, Watanabe $\mathrm{T}$ and Sugihara $\mathrm{K}$ : Causes of cancer death among first-degree relatives in Japanese families with Lynch syndrome. Anticancer Res 36: 1985-1989, 2016. PMID: 27069191.

11 Lindor NM, Rabe K, Petersen GM, Haile R, Casey G, Baron J, Gallinger S, Bapat B, Aronson M, Hopper J, Jass J, LeMarchand L, Grove J, Potter J, Newcomb P, Terdiman JP, Conrad P, Moslein G, Goldberg R, Ziogas A, Anton-Culver H, de Andrade M, Siegmund K, Thibodeau SN, Boardman LA and Seminara D: Lower cancer incidence in Amsterdam-I criteria families without mismatch repair deficiency: Familial colorectal cancer type X. JAMA 293: 19791985, 2005. PMID: 15855431. DOI: 10.1001/ jama.293.16.1979

12 Campos FG: Surgical treatment of familial adenomatous polyposis: Dilemmas and current recommendations. World J Gastroenterol 20: 16620-16629, 2014. PMID: 25469031. DOI: 10.3748/wjg.v20.i44.16620

13 Virgilio E, Di Gregorio F and Balducci G: Commentary on "clinical characteristics and adequate treatment of familial adenomatous polyposis combined with desmoids tumors". Cancer Res Treat 47: 339-340, 2015. PMID: 25725653. DOI: 10.4143/crt.2015.038

14 Syngal S, Brand RE, Church JM, Giardiello FM, Hampel HL and Burt RW: ACG clinical guideline: Genetic testing and management of hereditary gastrointestinal cancer syndromes. Am J Gastroenterol 110: 223-263, 2015. PMID: 25645574. DOI: 10.1038/ajg.2014.435

15 Balmaña J, Balaguer F, Cervantes A and Arnold D: Familial riskcolorectal cancer: ESMO clinical practice guidelines. Ann Oncol 24: 73-80, 2013. PMID: 23813931. DOI: 10.1093/annonc/ mdt209

16 Church J and Simmang C: Practice parameters for the treatment of patients with dominantly inherited colorectal cancer (familial adenomatous polyposis and hereditary nonpolyposis colorectal cancer). Dis Colon Rectum 46: 1002-1012, 2003. PMID: 12907889. DOI: 10.1097/01.DCR.0000080143.71778.AF

17 Palumbo P, Amatucci C, Perotti B, Dezzi C, Girolami M, Illuminati $G$ and Angelici AM: The Lynch syndrome: A management dilemma. Anticancer Res 33: 2147-2152, 2013. PMID: 23645768. 
18 Pistorius SR, Nagel M, Kruger, S, Plaschke J, Kruppa C, Wehrmann U, Schackert HK and Saeger HD: Combined molecular and clinical approach for decision making for surgery in HNPCC patients: A report on three cases in two families. Int J Colorectal Dis 16: 402-407, 2001. PMID: 11760904.

19 Buie WD and MacLean AR: Hereditary nonpolyposis colorectal cancer. In: Inherited Cancer Syndromes: Current clinical management. Ellis CN (ed.). New York, Springer New York, pp. 161-179, 2011.

20 Smith KD and Rodriguez-Bigas M: Role of surgery in familial adenomatous polyposis and hereditary nonpolyposis colorectal cancer (Lynch syndrome). Surg Oncol Clin N Am 18: 705-715, 2009. PMID: 19793576. DOI: 10.1016/j.soc.2009.07.006
21 Liska D and Kalady MF: Colorectal surgery in Lynch syndrome patients: When and how? Curr Colorectal Cancer Rep 11: 45-53, 2015. DOI 10.1007/s11888-015-0262-9

22 Sammour T, Hayes IP, Hill AG, Macrae FA and Winter DC: Familial colorectal cancer syndromes: An overview of clinical management. Expert Rev Gastroenterol Hepatol 9: 757-764, 2015. PMID: 25779305. DOI: 10.1586/17474124.2015.1026328

Received April 14, 2019

Revised May 3, 2019

Accepted May 7, 2019 